\title{
LARY NX.
}

Boulay.-Compressed Air Insuffator. "Arch. Internat. de Laryng., Otol., et Rhinol.," May and June, I 897.

Tile author has found the somewhat prolonged blast of air inseparable from the use of the ordinary instrument with india-rubber bellows to cause laryngeal distress and spasm. He has therefore devised an instrument in which air is compressed in a small metal reservoir. On pressing a trigger a blast of air of momentary duration is produced.

Wagsett.

Graham, J. E.-Broncho-Biliary Fistula, with the Reports of Two Cases. "Brit. Med. Journ.," June 5, I 897.

CASE I. Illness preceded by hepatic pain two and a half years before, and charac. terized by free coughing of bile, increased hepatic dulness, pleuritic friction on the right side, and light grey motions. Apparent complete recovery lasting ten years. Then followed a relapse, and on the patient showing signs of general failure an operation was performed. The hepatic and common bile ducts were found to be distended with gall stones. Cholecystenterostomy was performed, making use of the hepatic flexure instead of the duodenum. Patient died twelve days after from intercurrent complications: hæmoptysis, epistaxis, etc. No post-mortem was obtained.

The second case followed a kick from a horse, received over the cartilages of the fifth, sixth, seventh, and eighth ribs, and was characterized by pain, pneumonia, and bile-stained serum in the right pleural cavity. Bilious vomiting first appeared eighteen days after the accident. Two operations were performed, and through the two openings so produced bile and mucus escaped. Patient is now slowly recovering.

The author also refers to Courvoisier's twenty-four collected cases, to which he has added ten. Of these ten, two were due to hydatids and the remaining eight to biliary calculi. He also details the various ways in which cholelithiasis may cause broncho-biliary fistulae.

(K. M. Fenn) Hilligan.

Hogarth, R. G.-Remarks on the Treatment of Cut-Throat, with Notes of a Case Treated by Immediate Suture in Layers. "Brit. Med. Journ.," Aug. 21, 1897 .

THE author has had under treatment seven cases of cut-throat. In one case the wound was situated above the hyoid bone, in three in the thyro-hyoid membrane, in one in the crico-thyroid membrane, and in one in the trachea. Only full notes of one case are given, in which an extensive wound existed opening up the pharynx and larynx by dividing the thyro-hyoid membrane. The treatment consisted in accurate suturing of the divided tissues layer by layer, after the parts had been thoroughly cleansed. Chromic catgut was used for the deeper sutures, and horsehair for the skin wounds. The author thinks that cases of cut-throat should be treated by immediate suture, unless the patient is in a dying condition from shock and loss of blood. It is very rarely necessary to give chloroform, the accompanying depression of the nervous system being so great that the wound can be readily manipulated and apparently without pain. Usually primary union follows. The author also considers that it is never necessary to put in a tracheotomy tube at the time of suturing the wound. Should cedema of the larynx and dyspnoea subsequently ensue, a tracheotomy tube can then be inserted. The head should be kept inclined slightly forward and kept fixed. Much depends upon good nursing and judicious feeding.

W. Milligan. 
Noltenius (Bremen). - Removal of a Foreign Body from the Air Passages of a Boy aged four. "Archiv fur Laryngologie und Rhinologie," Bd. VI., Heft I.

Two days before the patient was seen by the author he had aspirated a glass bead about the size of a pea into his trachea. The foreign body was evidently movable, for with each attack of coughing a characteristic valve-like "flop" could be heard. As it was found impossible to remove the bead per zias naturales, either by instruments or by inversion of the patient, tracheotomy was recommended. Before this could be undertaken, however, the boy had a violent attack of choling, owing to the bead having slipped into the left bronchus, which it completely blocked. The trachea was now opened and coughing excited, but the body was not expelled.

The following day the bead was felt with the probe, in the division of the left bronchus going to the lower lobe; its position was confirmed by auscultation. Attempts were made to dislodge the bead with the probe, and to aspirate it with a Nelaton's catheter passed over the probe, but without success.

As the patient's general condition was good the canula was removed, and nothing further tried. Two days later, after an attack of suffocation, it was found that air was again entering the whole of the left lung, and that the bead was moving up and down in the trachea. The edges of the wound were now held apart, and the bead removed with forceps.

The bead, which was facetted and measured eight millimètres in diameter, had thus been six days in the air passages without giving rise to any noteworthy symptoms of irritation.

A. B. Kelly'.

Richel.-Injections of Hot Water and Medicated Fluids into the Lungs through the Trachea. Soc. de Biol. " Presse Méd.," July 3 I.

WATER at the temperature of $60^{\circ} \mathrm{C}$. can be injected without ill effect, and even at $65^{\circ} \mathrm{C}$. death does not follow. The lungs, however, appear to be very sensitive to antiseptic solutions, and iodine should not exceed '025 gr. ; sublimate $0025 \mathrm{gr}$. to the litre.

lVaggett.

Salzburg, S. (Berlin).-Is there a Hamorrhagic Laryngitis? "Archiv fur Laryng. und Rhinol.," Bd. V.

TrE author restricts the term hrmorrhagic laryngitis to bleedings beneath the mucous membrane or on its uninjured surface. It would be incorrect, however, to designate all laryngeal hemorrhages by this name, even if the mucous membrane were uninjured, for the term laryngitis indicates the presence of an inflammatory affection. Hemorrhages in consequence of injury, or artificially produced in the treatment of catarrh, do not therefore fall under this category. Similarly, traumatic hæmorrhages due to straining the voice, sudden vomiting, and whooping cough, and bleeding from varicose vessels in the larynx, must be left out of account. Further, hæmorrhages in hysterical or neurotic persons, and at the menstrual period - unless accompanied by catarrh-have no claim to the term. Cases in which the cause cannot be determined should be designated hemorrhagia laryngis rather than laryngitis hæmorrhagica.

Hæmorrhages do not occur solely in laryngitis sicca. The author has seen ten cases of laryngitis hæmorrhagica, in five of which there was laryngitis sicca, while in the other five, acute or chronic catarrh was present. In eighty-nine cases of laryngitis sicca, hæmorrhages were observed only in the five referred to.

In the author's opinion the bleedings accompanying the loosening of the crusts are caused by the increased pressure in the vessels due to coughing, the diminished elasticity of their walls, and the lessened support of the surrounding tissues in consequence of the catarrh. As to the cause of laryngitis hæemorrhagica, the author 
holds Rethi's view, attributing it to the great swelling and hyperplasia of the mucous membrane, the increase in size and number of the vessels, the lessened resistance of their walls, and the frequent and periodically increased blood-pressure from coughing, hawking, etc.

The etiology is the same as of chronic catarrh. As the affection is chiefly seen in women, and as the most severe hæemorrhages have been observed during menstruation and pregnancy, it is evident that the explanation is to be found in the changes the vessels of these persons undergo. The condition frequently occurs in purpura hæmorrhagica and cirrhosis of the liver; pseudo-leukiemia and atheroma are also causes.

Every idiopathic laryngeal catarrh is therefore entitled to be termed laryngitis hemorrhagica which, without external cause and with intact mucous membrane, is accompanied by hæmorrhages on or into the mucous membrane. A. B. Kelly.

Vallas.-Mcdian Osteotomy of the Hyoid. "Presse Méd.," July 17. Soc. de Chir. de Lyon.

THE author proposes this proceeding as a means of reaching foreign bodies, tumours of the epiglottis, pharyngeal strictures, etc., in the place of sub-hyoid pharyngotomy. After division of the hyoid, malignant disease at the base of the tongue can be freely dealt with. The author states that reunion of the fragments is completed in three weeks.

Wagsett.

\section{THYROID, \&C.}

Chauffard and Quéun. - Bilateral Resection of the Cervical Sympathetic in a Case of Exophthalmic Goitre. " Presse Méd.," July 3.

THE case reported is particularly interesting at the present time, as although the superior ganglion and four centimetres of the nerve below it on either side were removed (microscopic examination), no physiological phenomena resulted beyond a temporary myosis, while the course of the disease was unaffected. Waggett.

Doyen.-Removal of the Thyroid Body for Exophthalmic Goitre. Acad. de Méd. " "Presse Méd.," July 28.

Two well-marked cases were reported, from whom had been removed the whole of the enlarged gland with the exception of a piece the size of an almond. Cure remained complete after two and a half years, and four months, respectively. The first patient had, some months after operation, taken sheep's thyroid on her own responsibility. Palpitation, enervation, and exophthalmia thereupon reappeared, but ceased as soon as the drug was discontinued. The author asks why section of the sympathetic should be resorted to when removal of part of an over-secreting gland is so clearly indicated.

Waggett.

Péan.-Treatment of Exophthalmic Goitre by Resection of the Cervical Sympathetic. Acad. de Méd. "Presse Méd.," Aug. 4.

EXOTHYRopexy was dangerous, and not to be compared in efficiency to thyrodectomy. The speaker had resected the sympathetic in one case, and obtained diminution of pressure symptoms, but no effect on the nervous elements of the disease.

$$
\text { Wagsett. }
$$

Poncet.-Treatment of Exophthalmic Goitre hy Resection of the Ceraical Sympathetic. Acad. de Mérl. " P'rense Méd.," July 28.

THE author had operated on nine female cases. Benefit sometimes lasting, some- 